\title{
EL PAPEL DE LA AGRICULTURA PARA REVERTIR CONDICIONES DE MARGINACIÓN Y POBREZA EN MUNICIPIOS INDÍGENAS DE MÉXICO
}

THE ROLE OF AGRICULTURE TO REVERSE CONDITIONS OF MARGINALIZATION AND POVERTY IN INDIGENOUS MUNICIPALITIES OF MEXICO

\author{
Alejandro López Mercado \\ Instituto Politécnico Na- \\ cional, México \\ almloma@yahoo.es
}

\author{
Mara Rosas Baños \\ Instituto Politécnico \\ Nacional, México \\ mrb_ec@yahoo.com.mx
}

\author{
Hazael Cerón Monroy \\ Universidad Anáhuac \\ México/ \\ Instituto Politécnico \\ Nacional, México \\ hazaelceron@gmail.com
}

\section{RESUMEN}

Históricamente los municipios indígenas se han encontrado de una manera desproporcionada entre los sectores más pobres y marginados de la sociedad. En este documento se analiza el caso de 84 municipios indígenas en México que han logrado mejorar sus condiciones de marginación, pobreza e Índice de Desarrollo Humano. La aproximación teórica analiza el papel de la agricultura en las comunidades rurales, las formas de organización social y las oportunidades para un desarrollo socioeconómico autogestivo. Se realizó un análisis de relación estadística (Correlación de Pearson) entre la producción agrícola e índice de marginación, datos de pobreza e IDH. Los resultados arrojan evidencia de que existen una correlación negativa entre la producción agropecuaria con la pobreza y la marginación y una positiva en el IDH de estos 84 municipios indígenas estudiados. 
Palabras clave: municipios indígenas, producción agrícola, pobreza, índices de marginación, nueva ruralidad.

JEL: Q000

\begin{abstract}
Historically indigenous municipalities are positioned, disproportionately, among the poorest and most marginalized sectors of society. This document analyzes the case of 84 indigenous municipalities in Mexico, that have improved their conditions of marginalization, poverty and Human Development Index. Theoretical approach examines the role of agriculture in rural communities, forms of social organization and opportunities for automanaging its socioeconomic development. It has been made an analysis of statistical relationship (Pearson correlation) between agricultural production and the marginalization index, poverty data and HDI. The results show evidence that there is a negative correlation between agricultural production with poverty and marginalization; and positive correlation with the HDI of these 84 indigenous municipalities of the study.
\end{abstract}

Keywords: indigenous municipalities, agricultural production, poverty, marginalization rates, new rurality.

\title{
1. INTRODUCCIÓN
}

De acuerdo con varios estudios, las condiciones de vida de la población indígena de América Latina se encuentra por debajo del promedio del resto de la población y presenta elevados índices de pobreza junto con un limitado acceso a servicios públicos como educación y salud (Hall y Patrinos, 2006; Banco Mundial, 2005). El caso de México no es diferente, el Programa de las Naciones Unidas para el Desarrollo (PNUD) en su informe sobre Desarrollo Humano México estableció la relación inversa existente entre población indígena y desarrollo humano: a mayor población indígena 
menor desarrollo, a mayor desarrollo menor población indígena (PNUD, 2005: 60). No obstante, a pesar de las condiciones sumamente adversas, existe evidencia de que a finales del siglo pasado surgieron una serie de proyectos productivos en comunidades indígenas que estaban generando una mejora en sus condiciones de vida (Rodríguez y Alvarado, 2008; Bray y Merino, 2004; Barkin, 2004; Borrini et al., 2004; Gomero y Velásquez, 2003; Hillard et al., 2006; López, 2007; Mantilla, 2005; Murga, 2003; Reijntjes, 2009; Altieri y Toledo, 2011; Rosas y Lara, 2013). De acuerdo con el PNUD (2010: 32) incluso existen municipios cuya población indígena logra mayores niveles de desarrollo humano que la población no indígena. Generalmente, este tipo de mejoramiento se ha relacionado con la existencia de programas federales o de remesas de los migrantes.

El origen de esta investigación, precisamente, tiene su raíz en la indagación de los resultados de la política social en los municipios indígenas. El principal programa de lucha contra la pobreza indígena del gobierno de Felipe Calderón (2006-2012) fue la Estrategia 100x100 que focalizó a 125 municipios indígenas. De acuerdo con el Consejo Nacional de Evaluación de la Política de Desarrollo Social, Coneval (2013: 20) se invirtieron en dicho programa 39,544 millones de pesos entre 2007 y 2011. Los resultados arrojaron que de los 125 municipios focalizados 123 continuaron bajo la condición de muy alto grado de marginación, un municipio empeoró al pasar de marginación alta a muy alta y solamente uno mejoró su condición al pasar de marginación alta a media. Incluso, de los 125 municipios indígenas 50 de ellos no sólo no lograron mejorar su índice de desarrollo humano (IDH) en el periodo 2005-2010, sino que decayó. A partir de la indagación sobre las condiciones de marginación, pobreza e IDH de los 468 municipios destacadamente indígenas que existen en México, se encontró que 84 habían mejorado sus índices de marginación, pobreza e IDH y no estaban en la Estrategia 100x100; en lo que respecta a la migración internacional, de los 84 municipios indígenas sólo 19 presentan alta y muy alta intensidad migratoria en el año 2010, mientras que los otros 65 municipios presentan muy baja, baja y media intensidad migratoria (Conapo, 2012). 
El análisis socioeconómico estadístico de los 84 municipios muestra que entre los años 2000 y 2010 la marginación se redujo 66\%; la pobreza alimentaria $22 \%$, el IDH se incrementó en casi $13 \%$; el PIB per cápita creció 55\%; el valor de la producción agrícola entre los años 2005 y 2012 aumentó $70 \%$ más adelante se muestran las gráficas comparativas. En varios casos, el crecimiento de estos indicadores económicos es muy superior al experimentado a nivel nacional. La pregunta que se desprende de tales datos es ¿cómo es que estos municipios han logrado crear tales condiciones?

La hipótesis se sustenta en una revisión teórica en el ámbito de la sociología rural que destaca la importancia de la producción agrícola campesina y la nueva ruralidad comunitaria que resalta la capacidad de las comunidades indígenas y campesinas para generar sus propios modelos de desarrollo, los cuales están sustentados en su forma de organización social, el papel que la agricultura siempre ha tenido en las comunidades rurales y una lógica particular de gestión (Barkin y Rosas, 2006; Rosas y Fuente, 2013; Rosas y Lara, 2013; Toledo, 1992).

Específicamente, en el análisis se intenta demostrar la siguiente hipótesis: la mejora en los niveles de vida de la población que reside en los 84 municipios indígenas está asociada directamente con el crecimiento que experimentaron dichos municipios en el valor de la producción agrícola que han generado de 2000 a 2010, al crear no sólo mayores ingresos per cápita, sino mejores condiciones de marginación, pobreza y desarrollo humano.

El artículo se divide en tres apartados, en primer lugar se presenta una revisión teórica en el ámbito de la sociología rural que destaca la importancia de la producción agrícola campesina. Se revisan las aportaciones de la nueva ruralidad comunitaria que resalta la capacidad de las comunidades indígenas y campesinas para generar sus propios modelos de desarrollo, los cuales están sustentados en su forma de organización social; se muestra que la agricultura siempre ha tenido un papel importante en las comunidades rurales y una lógica particular de gestión (Barkin y Rosas, 2006; Rosas y Fuente, 2013; Rosas y Lara, 2013; Toledo, 1992). En segundo lugar, se presenta la metodología que se utiliza para probar la hipótesis que consiste en un análisis de correlación de Pearson. En tercer lugar, se muestran los datos de pobreza, marginación e IDH de los 84 
municipios indígenas de estudio y se comparan con el comportamiento del total de municipios eminentemente indígenas en México, en el caso del PIB per cápita además se muestra una comparación con la media nacional. Se presentan los datos del valor de la producción agrícola total así como la de la producción agrícola dividida en agricultura perenne y cíclica; la superficie cosechada y sembrada, además de los resultados del análisis de correlación propiamente. Finalmente se concluye que existe una correlación negativa entre el crecimiento del valor de la producción agrícola y la disminución de la marginación, en el caso de la pobreza los resultados no son robustos pero se mantiene la correlación negativa. La evidencia estadística más robusta se presenta en el análisis de correlación entre el IDH y el crecimiento del valor de la producción agrícola.

\section{SOCIOLOGÍA RURAL Y NUEVA RURALIDAD}

Dentro de los diversos modelos de desarrollo rural existentes en México se encuentra el llamado modelo modernizador, mismo que se basaba en la existencia de relaciones de intercambio desigual de precios con otros sectores de la economía para favorecer la industrialización y modernización del país (Torres y Delgadillo, 2009: 108). Modelo que, de acuerdo con Rubio (2004), entró en crisis en los años setenta y coincidió con el surgimiento de diversos movimientos campesinos e indígenas que demandaban recursos productivos para fortalecer sus sistemas de producción.

El modelo de promoción de exportaciones que sustituye al modelo económico anterior introdujo una serie de medidas de liberalización de los mercados con efectos todavía más adversos para el sector agropecuario del país; los campesinos quedaron cada vez más excluidos de la economía de mercado (Rubio, 2004: 5). Las políticas de cambio estructural para el sector rural buscaban la erradicación de las economías de subsistencia a través de modificaciones constitucionales relacionadas con los derechos de propiedad de la tierra ejidal, la reducción del crédito público y el desmantelamiento de la Compañía Nacional de Subsistencias Populares (Conasupo). Políticas que obligaron a una serie de transformaciones en las comuni- 
dades rurales, pero que, sin embargo, "no han provocado modificaciones sustanciales en la estructura de la producción agropecuaria de México, ni un profundo proceso de privatización de los derechos de propiedad de la tierra dedicada a la actividad agrícola" (Yúnez, 2010: 12)

El modelo actual de acumulación ha modificado la estructura productiva del sector rural y su base material (Rubio, 2004). La nueva ruralidad (NR) se propone el estudio, precisamente, de esa nueva relación y sus efectos, de acuerdo con Pérez (2001: 17) "las sociedades rurales han presentado cambios estructurales, debidos en buena parte al modelo de desarrollo global. Estos cambios hacen que tengamos que ver y analizar lo rural de distinta forma y, en esta medida, que las definiciones y estrategias del desarrollo rural". La nueva ruralidad presenta diversos enfoques, el que llamaremos ortodoxo considera a los actores sociales de los territorios rurales como sujetos pasivos, sostiene que los campesinos no han desaparecido porque no existen opciones laborales para ellos (Grammont, 2004). En esta perspectiva se considera que la población rural no puede mejorar sus condiciones de vida al mantener el modo de producción campesino, pero, al mismo tiempo, plantea que se presenta una "inexistencia de alternativas de trabajo asalariado y de políticas públicas que les aseguren la posibilidad de abandonar la actividad agrícola" (Grammont 2004: 284) por lo que se da un "aumento de la pobreza en la zona rural como resultado de la incapacidad de la organización tradicional de responder a los retos de la integración internacional" (Grammont, 2004: 284).

Por otro lado, se encuentra el enfoque que llamaremos heterodoxo, la nueva ruralidad comunitaria, el cual aporta elementos para entender el papel de los actores rurales desde su propia lógica, basada en una concepción de autonomía, que les permite reorientar sus actividades productivas y así mejorar los términos de intercambio con otros territorios y sectores sociales (Barkin, 2001; Fuente, 2009; Rosas y Fuente, 2013; Mora y Cerón, 2015). Pero estos cambios se encuentran precedidos de lo que Toledo (1996) llama desarrollo comunitario sustentable, el cual se entiende como un proceso de carácter endógeno a través del que una comunidad toma o recupera el control de los procesos que la determinan o que la afectan. Son seis procesos que las comunidades indígenas deben retomar para tener el control de su 
propio desarrollo: control de su territorio, de sus recursos naturales, de sus valores culturales, el control del mejoramiento de la calidad de vida de todos sus miembros, la regulación de sus intercambios económicos, así como el control de sus propias formas de organización política. Pero no solo eso, Toledo (2008) también explica que, para sobrevivir, las unidades de producción campesinas deben tener una "exitosa articulación tanto con los procesos ecológicos como con los procesos económicos... debe jugar de manera exitosa una doble partida, y modificar su estrategia ante las cambiantes situaciones" (Toledo, 2008: 20).

A partir de dicho control empezó a surgir un incremento en la diversificación de actividades productivas fuertemente relacionada con la dotación del patrimonio natural con el que cuentan las comunidades rurales (Barkin, 2001), que reorienta su propio esquema de producción y les permite mejorar las condiciones de vida de su población (Mora y Cerón, 2015; García y Quintero 2009: 200). Esta diversificación productiva se presenta con una modificación en los mercados de trabajo dentro del concepto rururbanización, es decir, con la incorporación de mujeres a los mercados laborales de espacios aledaños al territorio rural, sin que esto implique migración definitiva o abandono de los territorios rurales (Grajales y Bórquez, 2009: 156). Sin embargo, es necesario remarcar el hecho de que se mantiene la producción agrícola campesina, no desaparece debido a que la producción agropecuaria tiene un papel estratégico para las comunidades rurales (Van der Ploeg, 2011). Las familias campesinas siguen obteniendo parte o la totalidad de sus ingresos a través de la producción agrícola campesina, además de que históricamente ha sido un mecanismo de combate a la pobreza y al hambre.

Dentro de este enfoque se pueden ubicar las racionalidades socioproductivas no capitalistas, que buscan el bien común y la construcción de sociedades más equitativas y justas basadas en unidades de producción y consumo; esto es, que consumen lo que producen y no buscan la acumulación de riqueza, sino elevar las condiciones de vida familiar y colectiva (Marañón y López, 2013: 13-15). Racionalidad que se contrapone a la económica instrumental capitalista, en la que existe la apropiación individual y privada de la riqueza que busca incrementar la producción 
a través de la reducción al máximo de los costos (Rosas y Barkin, 2009). En el caso de los pueblos y comunidades indígenas el concepto de las racionalidades no capitalistas está estrechamente vinculado con el de comunalidad que, de acuerdo con Díaz (2004) y Martínez (2011) es la manera de pensar de los pueblos indígenas, su cosmovisión respecto a los valores fundamentales de su vida cotidiana. En ese sentido, el concepto de comunalidad implica una serie de elementos sustanciales, entre los que destacan: el espacio del territorio de la comunidad, el predominio del uso colectivo de los recursos y la toma de decisiones por consenso en asambleas comunitarias; entre otros.

\section{METODOLOGÍA}

A fin de confirmar la hipótesis de que la producción agropecuaria tiene una asociación negativa con la pobreza y la marginación y positiva con el IDH se realizó un análisis de relación estadística entre estas variables. En las relaciones estadísticas entre variables se analizan, en esencia, variables aleatorias o estocásticas, es decir, variables con distribuciones de probabilidad. Por ejemplo, el rendimiento de un cultivo depende de la temperatura, lluvia, sol y fertilizantes, y dicha dependencia es de naturaleza estadística porque las variables asociativas al fenómeno, si bien son importantes, no permiten al agrónomo predecir en forma exacta el rendimiento del cultivo debido a los errores propios de la medición de dichas variables y a otra serie de factores (variables) que en conjunto afectan el rendimiento pero son difíciles de identificar individualmente (Gujarati y Porter, 2010). De esta manera habrá una variabilidad intrínseca o aleatoria entre las variables, que, con base en el mismo el ejemplo, la producción del cultivo no podrá explicarse en su totalidad sin importar cuántas variables explicativas se consideren.

En el presente estudio, al saber que la pobreza, la marginación y el IDH están asociados a otro tipo de variables, se confirmará mediante un análisis de correlación de Pearson que la producción agrícola sí tiene niveles de asociación muy altos con las variables en cuestión. Para ello 
se utilizó el análisis de correlación que, por principio de parsimonia, sólo utilizará dos de las variables, es decir el valor de la producción agrícola con cada una de las variables señaladas.

En el análisis de correlación de Pearson el objetivo principal es medir la fuerza o el grado de asociación lineal entre dos variables " $x$ " $y$ " $y$ ". El coeficiente de correlación " $r$ " mide esta fuerza de asociación lineal, donde las variables se tratan de forma simétrica. El índice de correlación de Pearson (Freund y Simon, 1994) se calcula de la siguiente forma:

Donde:

$$
\begin{aligned}
r_{x y}= & \frac{\sum x y}{\sqrt{\sum x^{2}} \sqrt{\sum y^{2}}} \\
& =X-\bar{X} \\
y & =Y-\bar{Y}
\end{aligned}
$$

El coeficiente de correlación es la covarianza parametrizada de dos variables en un rango de valores entre -1 y 1 pasando por el valor de 0 , lo que indica un estatus incorrelacionado entre variables. Con esta fórmula fueron calculados los coeficientes de correlación de Pearson entre producción agropecuaria y pobreza, producción agropecuaria $\mathrm{y}$ marginación y, por último, producción agropecuaria e IDH.

Asimismo, se realizaron pruebas de hipótesis $t$ de Student de los coeficientes obtenidos, para probar que estos valores sean significativamente diferentes de cero a los niveles de, 90, 95 y 99\% de significancia. El valor de $t$ se estima con la fórmula siguiente:

$$
1=\frac{\mathrm{r}_{\mathrm{xy}}-0}{\sqrt{\frac{1-r_{x y}^{2}}{N-2}}}
$$

Respecto a los datos que se utilizaron, estos fueron tomados de las fuentes correspondientes. En México la medición de la pobreza le corresponde al Consejo Nacional de Evaluación de la Política de Desarrollo Social (Coneval, 2012), del cual se obtuvieron los indicadores de pobreza 
alimentaria, de capacidades y patrimonial. El índice de marginación le corresponde al Consejo Nacional de Población (Conapo, 2012) y se tomó para los años 2000, 2005 y 2010, mientras que el IDH se consultó en el Informe sobre Desarrollo Humano de los Pueblos Indígenas publicado por el PNUD (2010). Ahora bien, respecto a la variable de producción agrícola se consideró el valor de la producción agrícola obtenida del Servicio de Información Agroalimentaria y Pesquera (SIAP, 2015) de la la Secretaría de Agricultura, Ganadería, Desarrollo Rural, Pesca y Alimentación (Sagarpa), deflactada a precios constantes de 2003 con el índice nacional de precios al consumidor.

En este estudio se identificaron las variables antes señaladas de 84 municipios que tienen dos características fundamentales: son municipios considerados como indígenas y además mejoraron sus condiciones de marginación. Los 84 municipios de nuestro estudio que mejoraron su condición de marginación se encuentran incluidos en los 468 eminentemente indígenas, con población de $70 \%$ o más hablantes de una lengua indígena.

La identificación de estos municipios se realizó con la clave de campo común llamada Clave Municipal (Cve_mun) que proporciona el Instituto Nacional de Estadística y Geografía (INEGI) compuesta por cinco dígitos, de los cuales los dos primeros corresponden a la clave de la entidad federativa y los tres siguientes a la clave del municipio. Posteriormente, para hacer la selección se identificó que los municipios hubieran cambiado su estatus a un mejoramiento, basta señalar que el índice de marginación se clasifica en cinco grupos de marginación con base en la técnica de Dalenius y Hodges (muy bajo, bajo, medio, alto y muy alto) (Conapo, 2010) y cuya estimación del índice se calcula bajo la técnica de componentes principales. Los municipios seleccionados se presentan en el cuadro 1.

Para realizar los comparativos entre años se realizaron los promedios de los índices de los 84 municipios con el año correspondiente. De acuerdo con Cortés y Vargas (2011) existe una limitación, ampliamente conocida, de que el índice de Conapo no permite conocer la trayectoria de la marginación de los municipios a lo largo del tiempo, sino que su utilidad radica en ordenar los municipios según rangos de marginación, para cada 
año en que se calcula. Sin embargo, para enfrentar dicha limitación se consultó un índice de marginación alternativo (Cortés y Vargas, 2013), que a la vez permitiera seguir la trayectoria de la marginación municipal en el tiempo y estuviera fuertemente correlacionado con el de Conapo. Esta última condición es importante desde el punto de vista aplicado, ya que garantiza que la jerarquización de los municipios al emplear uno u otro índice sea básicamente la misma, lo que permite utilizarlo y lograr resultados equivalentes a los que se alcanzan con el índice de marginación de Conapo; por lo que el cálculo de los promedios permite su comparabilidad a lo largo del tiempo en este índice en específico.

\section{RESULTADOS: SECTOR AGRÍCOLA Y DISMINUCIÓN DE POBREZA, MARGINACIÓN Y MEJORA DEL IDH}

Con base en la tipología de la Comisión Nacional para el Desarrollo de los Pueblos Indígenas (CDI, 2006: 13) en la actualidad los pueblos indígenas de México se encuentran distribuidos en 468 municipios, que se consideran básicamente indígenas por contar con una población de $70 \%$ o más hablantes de lenguas indígenas, tienen una población total de $5,283,947$, de los cuales $88.85 \%$ son hablantes de lenguas indígenas.

De los 468 municipios eminentemente indígenas se encontró que 84 municipios ubicados en ocho estados de la República presentan una tendencia decreciente en sus índices de marginación y pobreza entre los años 2000 y 2010 (CDI, 2011). 


\section{Cuadro 1}

Municipios indígenas que mejoraron sus condiciones de marginación

\begin{tabular}{|c|c|c|}
\hline Nombre entidad & $\begin{array}{l}\text { Número de } \\
\text { municipios }\end{array}$ & Nombre del municipio \\
\hline Campeche & 1 & Hopelchén \\
\hline Hidalgo & 3 & Cardonal, Huejutla de Reyes, Jaltocán \\
\hline Oaxaca & 33 & $\begin{array}{l}\text { Ayotzintepec, Tamazulápam del Espíritu Santo, } \\
\text { Ixtlán de Juárez, San Bartolomé Zoogocho, San } \\
\text { Cristóbal Lachirioag, San Ildefonso Villa Alta, } \\
\text { San Juan del Río, San Juan Guelavía, San Juan } \\
\text { Yatzona, San Miguel el Grande, San Miguel } \\
\text { Panixtlahuaca, San Pablo Macuiltianguis, San } \\
\text { Pedro Huilotepec, San Pedro Molinos, Santa } \\
\text { Lucía Ocotlán, Santa María Temaxcalapa, } \\
\text { Santa María Texcatitlán, Santa María Xadani, } \\
\text { Santa María Yalina, Santa María Yucuhiti, } \\
\text { Santiago Atitlán, Santiago Comaltepec, } \\
\text { Santiago Laxopa, Santiago Zoochila, Nuevo } \\
\text { Zoquiápam, Santo Domingo Petapa, Santos } \\
\text { Reyes Nopala, Santos Reyes Pápalo, Tanetze } \\
\text { de Zaragoza, Teococuilco de Marcos Pérez, } \\
\text { San Jerónimo Tlacochahuaya, Totontepec Villa } \\
\text { de Morelos, San Juan Bautista Valle Nacional; }\end{array}$ \\
\hline Puebla & 6 & $\begin{array}{l}\text { San Gabriel Chilac, San José Miahuatlán, } \\
\text { Xayacatlán de Bravo, Yaonáhuac, Zinacatepec, } \\
\text { Zoquiapan; }\end{array}$ \\
\hline Quintana Roo & 3 & $\begin{array}{l}\text { Felipe Carrillo Puerto, José María Morelos, } \\
\text { Lázaro Cárdenas }\end{array}$ \\
\hline San Luis Potosí & 3 & San Antonio, Tanlajás, Axtla de Terrazas \\
\hline Veracruz & 3 & Benito Juárez, Rafael Delgado, Zaragoza \\
\hline Yucatán & 32 & $\begin{array}{l}\text { Abalá, Akil, Bokobá, Calotmul, Cuzamá, } \\
\text { Dzán, Hocabá, Homún, Kantunil, Kinchil, } \\
\text { Kopomá, Mama, Maxcanú, Muxupip, } \\
\text { Opichén, Oxkutzcab, Peto, Sacalum, Samahil, } \\
\text { Sanahcat, Sotuta, Sucilá, Tahmek, Tecoh, } \\
\text { Tekax, Tekit, Tepakán, Teya, Tinum, Tizimín, } \\
\text { Tzucacab, Xocchel }\end{array}$ \\
\hline Total & 84 & \\
\hline
\end{tabular}

Fuente: Elaboración propia con datos de Conapo 2012 y CDI 2011. 
De acuerdo con el índice de desarrollo humano municipal 2010 del PNUD, los 84 municipios del presente estudio tuvieron en el año 2000 un PIB per cápita promedio de 4,180 dólares, que es superior al promedio de los 468 municipios indígenas de 3,186 dólares, lo que representa una diferencia de 31 por ciento. Esta diferencia aumenta para los años $2005 \mathrm{y}$ 2010, al pasar a un PIB per cápita de 6,462 dólares en 2005 y de 6,508 para el año 2010; mientras que el conjunto de los 468 municipios indígenas alcanza 4,916 dólares en 2005 y 5,036 en 2010. Esto es, para el año 2010 la diferencia en el PIB per cápita entre los 84 municipios analizados y el conjunto de los 468 municipios se incrementa para ubicarse en 39.2 por ciento. Por el contrario, la brecha existente entre el promedio nacional, que para el año 2000 era de $67.5 \%$ respecto al de los 84 municipios se reduce a $32.9 \%$ (ver gráfica 1$)$.

\section{Gráfica 1}

Producto interno bruto per cápita (dólares PPC, precios 2010)

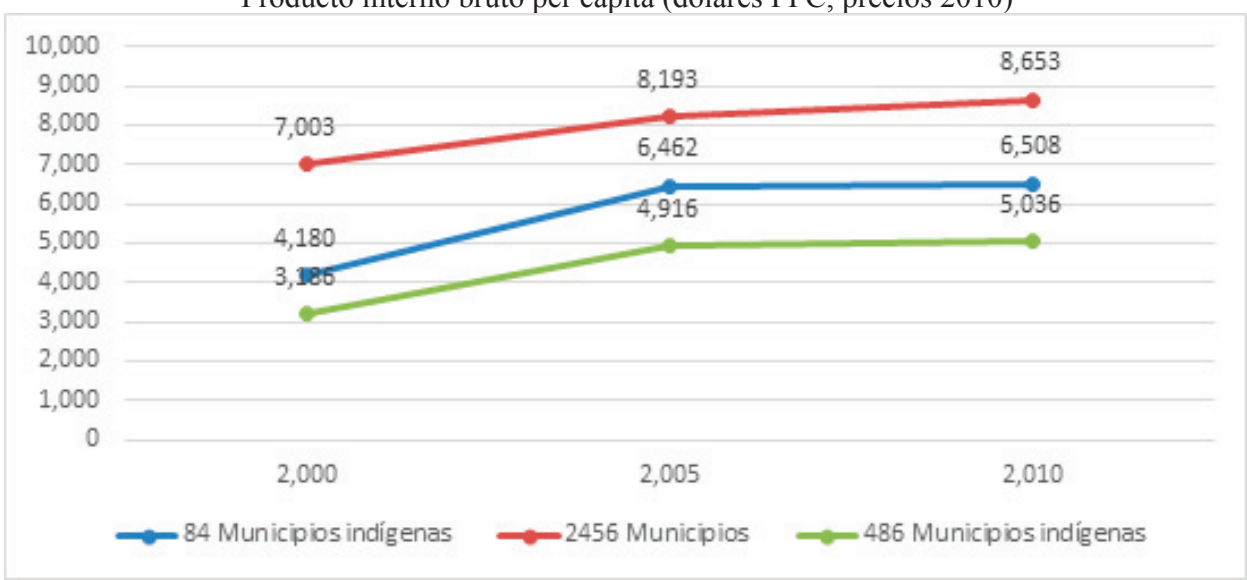

Fuente: Elaboración propia con datos de PNUD, 2014.

En la gráfica 2 se puede apreciar que, en promedio, el índice de marginación se redujo 66\% para los 84 municipios al pasar de un valor de 0.4126 en el año 2000 a 0.2749 para el año 2010, lo que significa que, en general, mejoraron sus condiciones de analfabetismo, educación, vivienda y población ocupada con ingresos de al menos dos salarios mínimos. 


\section{Gráfica 2}

Comparativo del índice de marginación de 84 municipios indígenas, 2000-2010

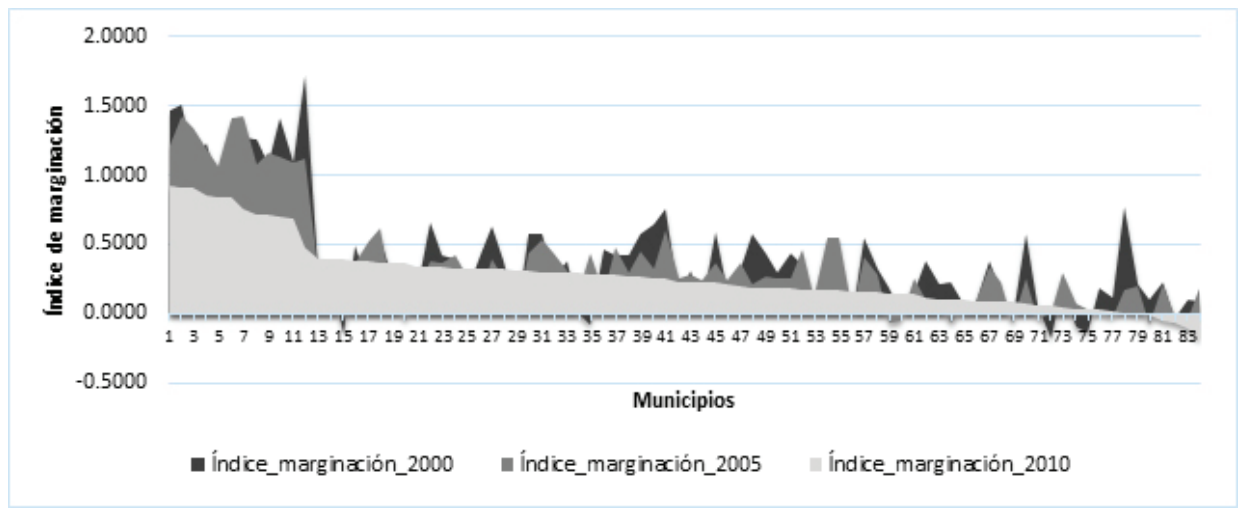

Fuente: Elaboración propia con datos de Conapo 2012 y CDI 2011.

Nota: La gráfica toma como base el índice de los 84 municipios de 2010, de mayor a menor.

Respecto a los niveles de pobreza en el periodo de 1990 a 2010 , según las mediciones de Coneval la pobreza en sus distintas categorías se ha mantenido casi sin variación en las dos décadas pasadas en los 468 municipios eminentemente indígenas. La pobreza alimentaria pasó de $54.3 \%$ en 1990 a $52.2 \%$ en 2010 , mientras que la pobreza de capacidades de $63 \%$ a $62.5 \%$ y la patrimonial se incrementó de $81.2 \%$ a $83.6 \%$. En cambio, los 84 municipios que analizamos presentan una tendencia negativa en la pobreza alimentaria y de capacidades, es decir, una mayor disminución: la pobreza alimentaria pasó de $44.2 \%$ en 1990 a $37.4 \%$ en 2010 , mientras que la pobreza de capacidades lo hizo de $53.5 \%$ a $48.3 \%$ (véase gráfica 3 ).

\section{Gráfica 3}

Comparativo de niveles de pobreza de municipios indígenas, 1990-2010 (Porcentajes)

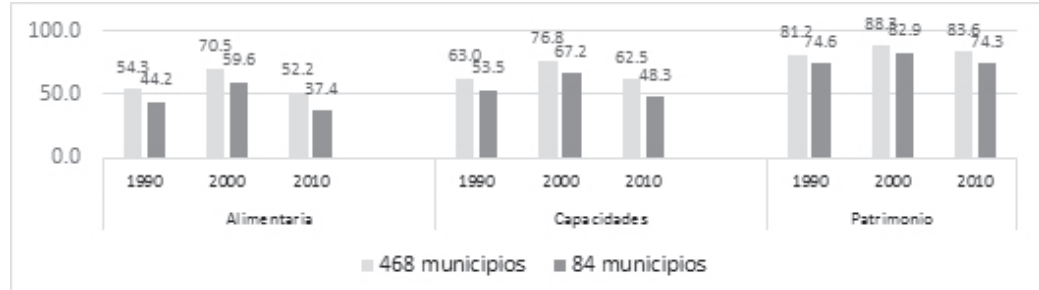

Fuente: Elaboración propia con datos de Coneval, 2012. 
De conformidad con los datos del PNUD 2014 y del IDH 2010, los 468 municipios eminentemente indígenas tuvieron un incremento o mejoría de $16 \%$ en relación con el IDH 2000. En el caso de los 84 municipios estudiados estos tenían un IDH de 0.6878 en el año 2000, que es mayor que el que tenía el resto de los municipios indígenas en ese mismo año, y en 2010 se ubicó en 0.7770 , lo que representó una mejora de $12.9 \%$ (véase gráfica 4).

\section{Gráfica 4}

Comparativo del valor medio del Índice de Desarrollo Humano de 84 municipios indígenas, 2000-2010

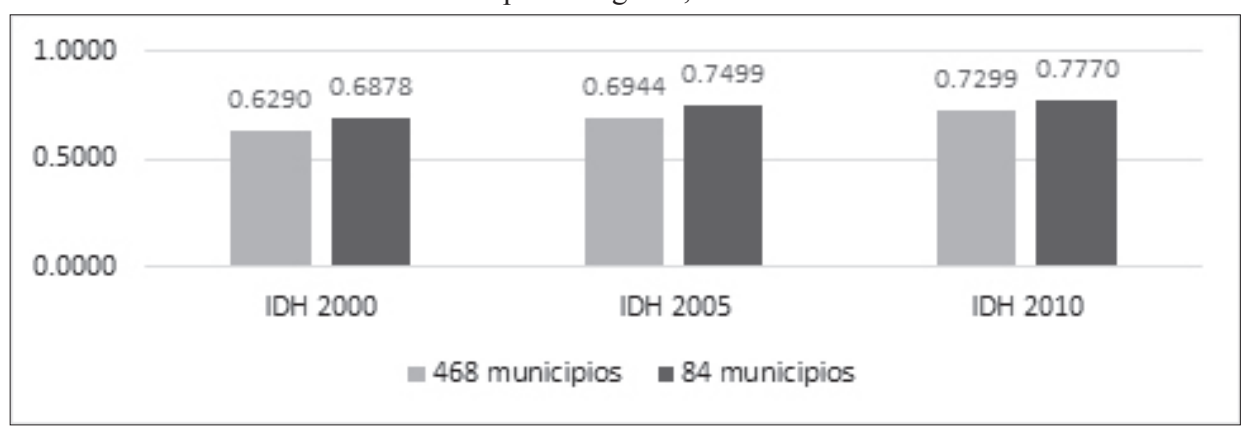

Fuente: Elaboración propia con datos de PNUD, 2010.

\subsection{La producción agrícola como vía de mejoramiento de marginación y pobreza en 84 municipios indígenas de México}

La extensión de tierra de los 84 municipios indígenas es de 6.7 millones de hectáreas, según el Censo agropecuario de 2007, esto equivale a $3.4 \%$ del territorio nacional. Del total se destinaron a la siembra agrícola 598,369 hectáreas en el año 2005 y 590,427 hectáreas en el año 2010, es decir, solo alrededor de $8.81 \%$ de la superficie con que cuentan; este dato es relevante en el ámbito de la racionalidad comunitaria (Rosas y Fuente, 2013) puesto que la expansión de tierra de cultivos es un factor de insustentabilidad ecológica. La superficie cosechada en 2005 fue de 544,884 y en 2010 de 571,520 hectáreas, lo cual muestra que, a pesar de que en 2010 hubo una superficie sembrada menor en 7,942 hectáreas, se 
cosechó una superficie mayor en este año lo que sugiere un incremento de la productividad en este sector.

Durante el año 2005 la producción agrícola en los municipios que se analizan fue de 480,769 toneladas, en una extensión de 598,369 hectáreas sembradas y 544,884 cosechadas (véase gráfica 5), mientras que para el año 2010 la producción se incrementó a 516,742 toneladas de productos en una extensión de 590,427 hectáreas sembradas y 571,520 cosechadas. Esto es, la producción aumentó 35,973 toneladas $(7.48 \%)$ en prácticamente la misma superficie de siembra, dato que incluye los cultivos cíclicos y los perennes estimados por la Sagarpa y presentados en el SIAP. ${ }^{1}$ En 2005, las 480,769 toneladas representaron 2,116.56 millones de pesos constantes y las 516,742 toneladas de 2010, 2,829.94 millones de pesos constantes, como valor de la producción agrícola.

\section{Gráfica 5}

Valor de la producción agrícola, superficie sembrada y cosechada de 84 municipios indígenas, 2005-2010

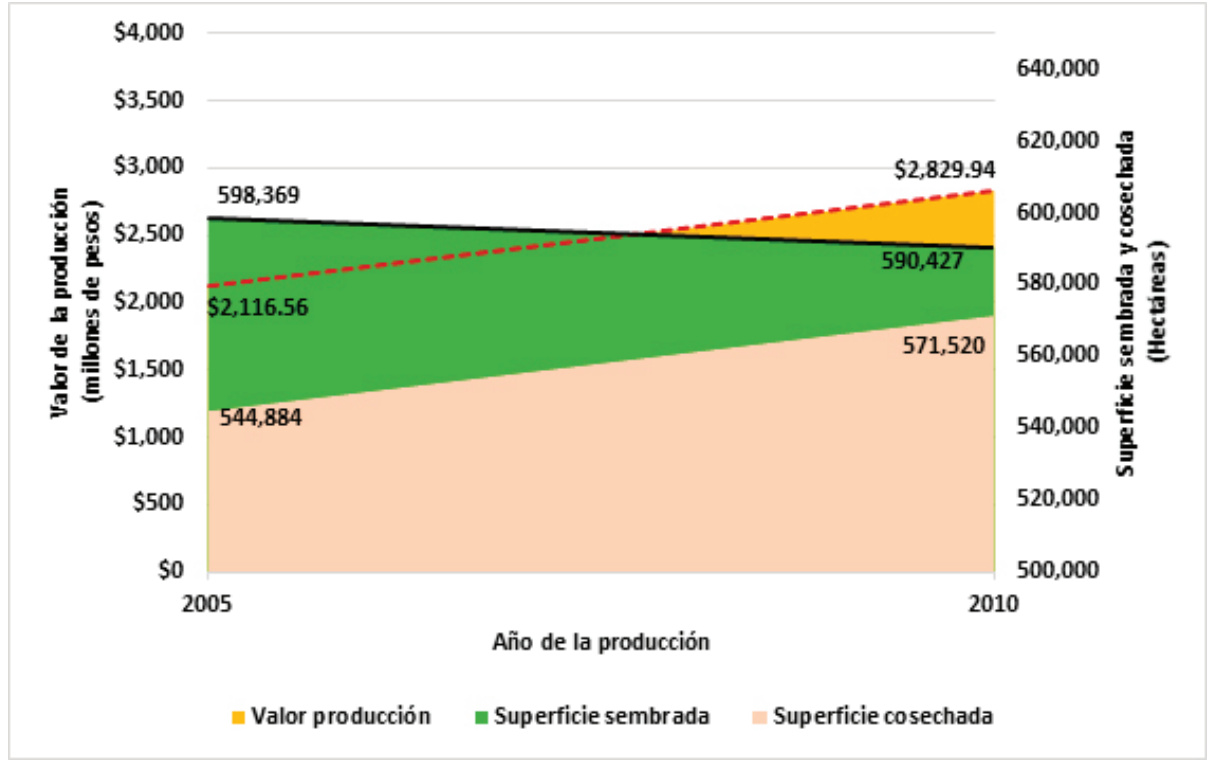

Fuente: Elaboración propia con datos del SIAP, 2005 y 2010.

1 El índice nacional de precios al consumidor para deflactar los valores de 2005 y 2010 fue de 108.863 y 135.229 , respectivamente, a precios de $2003=100$. 
Por lo que se refiere a los cultivos cíclicos, los principales productos en los 84 municipios indígenas fueron: el maíz, la soya y el frijol. El maíz representó en el año 2005, 92\% de la superficie destinada al cultivo, sin embargo, para 2010, dicho porcentaje se redujo a 88 por ciento. En cambio, la soya pasó de 2,325 hectáreas sembradas (1\% del total) a 9,853 hectáreas cosechadas $(4.2 \%$ del total), igual que otros productos que crecieron en superficie cosechada respecto al año 2005. En ese mismo sentido, y como ejemplo a nivel comparativo, se puede señalar que el precio promedio del maíz, como se verá más adelante, aumentó. El incremento del precio según la racionalidad económica neoclásica derivaría en generar incentivos para un incremento sustancial de la producción, pero en los municipios indígenas estudiados esto no sucedió, ya que se pasó de 351,445 toneladas en el año 2005 a 359,215 toneladas en 2010, lo que representó apenas un incremento de 2.2 por ciento.

Como lo señala la perspectiva de la nueva ruralidad (Barkin y Rosas, 2006; Rosas y Fuente, 2013), si bien en periodos en los que se da un deterioro en los precios de mercado es posible encontrar que se mantienen e incluso se incrementan los niveles de producción, también es factible que en periodos de incremento en los precios de mercado la producción se mantenga estable en las comunidades y pueblos indígenas.

La producción de cultivos perennes representa más de la mitad de la producción agrícola, aunque su importancia económica, en cuanto a ingresos para la población de los 84 municipios, es mayor. Para esta producción se destinaron 364,818 hectáreas en el año 2005, que representan 56\% más de las 233,549 hectáreas que se destinaron a los cultivos cíclicos, y aunque disminuyeron a 344,959 para 2010 siguen representando más de 100 mil hectáreas, comparadas con las 243,668 de los cultivos cíclicos para ese mismo año.

Los principales productos que se obtienen de estos cultivos son pastos (para la cría de ganado), naranja, café, caña de azúcar, limón, henequén, mandarina, maguey pulquero y papaya, que en conjunto representan poco más de $98 \%$ de la superficie cosechada, tanto en 2005 como en 2010. En cuanto al valor de la producción se pasó de 1,171.02 millones de pesos en 2005 a 1,463.75 millones de pesos constantes, lo que significó un crecimiento a una tasa media anual de 5\% (cuadro 2). Esta producción es la que se destina 
en su mayor parte a la comercialización, lo que permite a las comunidades indígenas incrementar sus ingresos corrientes.

\section{Cuadro 2}

Producción total y valor de producción de cultivos perennes, 2005 y 2010 de los 84 municipios seleccionados

\begin{tabular}{|l|r|r|r|r|r|r|}
\hline Cultivos & $\begin{array}{c}\text { Producción } \\
2005 \\
\text { (toneladas) }\end{array}$ & $\begin{array}{c}\text { Valor } \\
\text { producción } \\
2005 \\
\text { (millones } \\
\text { de pesos } \\
2003=100)\end{array}$ & $\begin{array}{c}\text { Participación } \\
\text { en el valor } \\
\text { total } \\
(\%)\end{array}$ & $\begin{array}{r}\text { Producción } \\
2010 \\
\text { (toneladas) }\end{array}$ & $\begin{array}{c}\text { Valor } \\
\text { producción } \\
2010 \\
\text { (millones } \\
\text { de pesos } \\
2003=100)\end{array}$ & $\begin{array}{c}\text { Participación } \\
\text { en el valor } \\
\text { total } \\
(\%)\end{array}$ \\
\hline Pastos & $2,655.51$ & 412.36 & 32.22 & $2,451.33$ & 396.17 & 24.82 \\
\hline Naranja & 218.98 & 118.36 & 9.25 & 256.33 & 182.21 & 11.41 \\
\hline Café cereza & 31.44 & 57.53 & 4.50 & 25.57 & 71.36 & 2.47 \\
\hline $\begin{array}{l}\text { Caña } \\
\text { de azúcar } \\
\text { otro uso }\end{array}$ & 125.07 & 35.07 & 2.74 & 149.51 & 45.84 & 2.87 \\
\hline Limón & 69.93 & 52.16 & 4.08 & 99.35 & 125.41 & 7.86 \\
\hline Henequén & 1.47 & 6.81 & 0.53 & 1.61 & 7.51 & 0.47 \\
\hline $\begin{array}{l}\text { Caña de } \\
\text { azúcar }\end{array}$ & 93.99 & 31.86 & 2.49 & 87.14 & 38.66 & 2.42 \\
\hline Mandarina & 9.43 & 4.28 & 0.33 & 9.16 & 10.68 & 0.67 \\
\hline $\begin{array}{l}\text { Maguey } \\
\text { pulquero } \\
\text { (miles de lts.) }\end{array}$ & 113.40 & 260.42 & 20.35 & 118.81 & 355.84 & 22.29 \\
\hline Papaya & 29.02 & 83.42 & 8.50 & 29.234 & 97.37 & 8.31 \\
\hline $\begin{array}{l}\text { Otros 43 } \\
\text { cultivos }\end{array}$ & 125.46 & 108.74 & 15.02 & 108.75 & 132.67 & 14.41 \\
\hline Total & $\mathbf{3 , 4 7 3 . 7 3}$ & $\mathbf{1 , 1 7 1 . 0 2}$ & $\mathbf{1 0 0 . 0 0}$ & $\mathbf{3 , 3 3 6 . 8 3}$ & $\mathbf{1 , 4 6 3 . 7 5}$ & $\mathbf{1 0 0 . 0 0}$ \\
\hline
\end{tabular}

Fuente: Elaboración propia con datos del SIAP, 2005- 2010.

En relación con los cultivos cíclicos, los principales productos en los 84 municipios indígenas fueron el maíz, la soya y el frijol. El maíz representó en $200591.96 \%$ de la superficie destinada al cultivo, no obstante, para 2010 dicho porcentaje se redujo a $88.23 \%$, aunque en términos absolutos prácticamente se destinó la misma superficie. En cambio, la soya pasó de 2,325 hectáreas cosechadas ( $1 \%$ del total) a 9,853 hectáreas (4.21\% del total), lo mismo que otros productos que crecieron en superficie sembrada respecto al año 2005 (cuadro 3). 


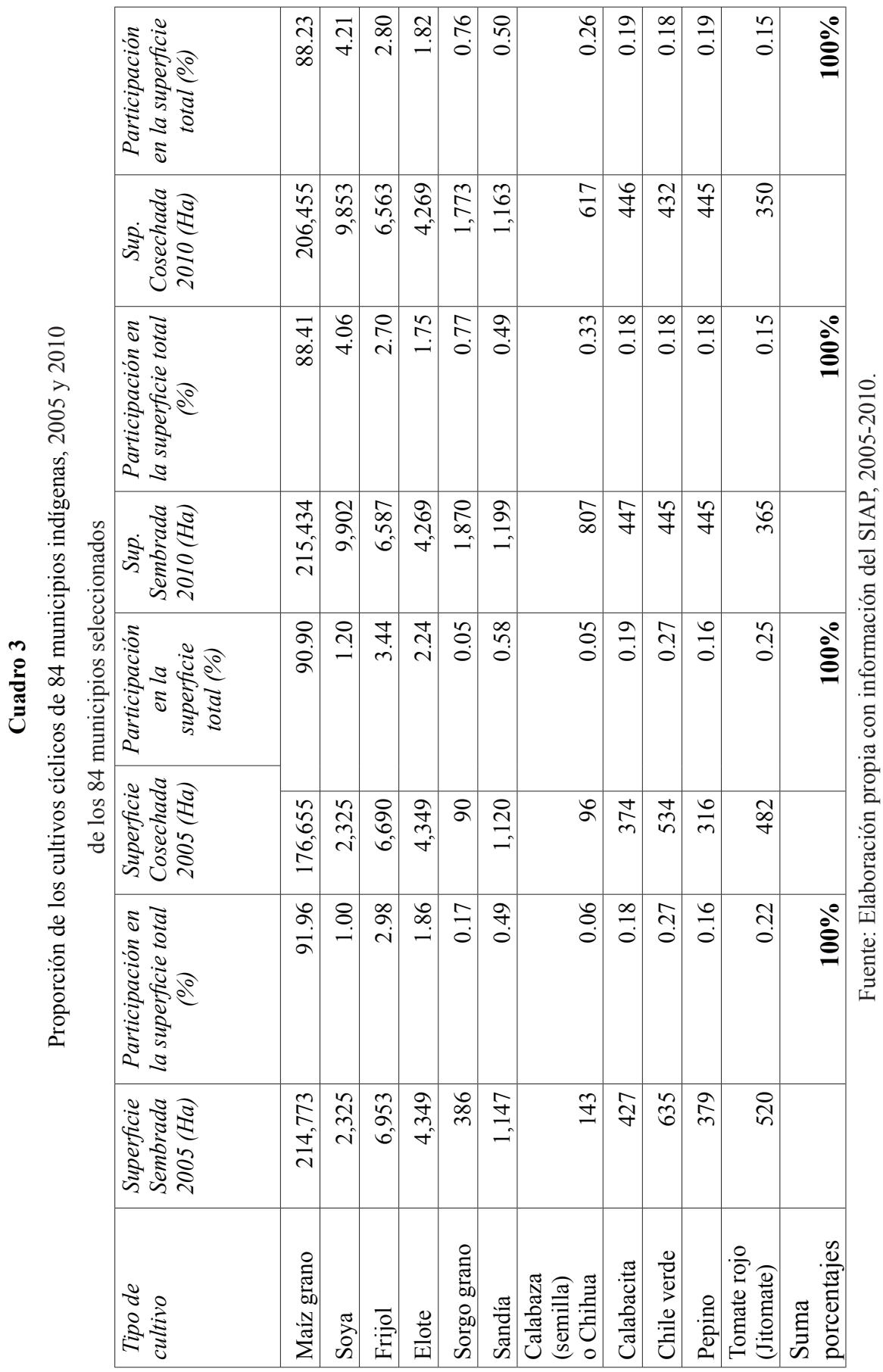

Julio a Diciembre de 2016 - Págs.: 37-68 
Se debe mencionar que el maíz aunque tuvo un rendimiento promedio de 1.19 toneladas por hectárea en 2005, éste disminuyó a 1.14 toneladas por hectárea en 2010 (véase cuadro 4). Sin embargo, en 32 de los 84 municipios se tuvieron rendimientos por encima de ese promedio, que en algunos casos supera las 3 toneladas por hectárea. En cuanto al valor de la producción agrícola, la producción de maíz representó $60.96 \%$ del total en 2005 , y se mantuvo casi en ese mismo nivel al pasar a $61.89 \%$ en 2010, aunque en términos monetarios el valor se incrementó en $47.73 \%$ al pasar de 572.362 millones de pesos constantes en 2005 a 845.572 millones constantes en 2010.

\section{Cuadro 4}

Rendimiento por hectárea y valor de la producción según tipo de cultivo cíclico, 2005-2010

\begin{tabular}{|c|c|c|c|c|c|c|}
\hline $\begin{array}{c}\text { Tipo } \\
\text { de cultivo }\end{array}$ & $\begin{array}{c}\text { Promedio de } \\
\text { Rendimiento } \\
2005 \text { (Ton/ } \\
\text { Ha) }\end{array}$ & $\begin{array}{c}\text { Promedio de } \\
\text { Rendimiento } \\
2010 \text { (Ton/ } \\
\text { Ha) }\end{array}$ & \begin{tabular}{|c|} 
Valor \\
producción \\
2005 \\
(Miles \\
de pesos \\
$2003=100)$ \\
\end{tabular} & $\begin{array}{l}\text { Proporción } \\
\text { respecto al } \\
\text { total (\%) }\end{array}$ & $\begin{array}{c}\text { Valor } \\
\text { producción } \\
2010 \text { (Miles } \\
\text { de pesos } \\
2003=100)\end{array}$ & $\begin{array}{l}\text { Proporción } \\
\text { respecto al } \\
\text { total (\%) }\end{array}$ \\
\hline Maíz grano & 1.19 & 1.14 & $572,362.93$ & 60.96 & $845,572.40$ & 61.89 \\
\hline Soya & 1.83 & 0.95 & $7,760.18$ & 0.83 & $47,399.48$ & 3.47 \\
\hline Frijol & 0.62 & 0.52 & $30,349.95$ & 3.23 & $27,672.25$ & 2.03 \\
\hline Elote & 5.69 & 8.32 & $30,515.29$ & 3.25 & $30,529.62$ & 2.23 \\
\hline Sorgo grano & 1.40 & 2.23 & 408.77 & 0.04 & $7,144.90$ & 0.52 \\
\hline Sandía & 15.63 & 10.43 & $29,023.52$ & 3.09 & $71,778.06$ & 5.25 \\
\hline $\begin{array}{l}\text { Calabaza } \\
\text { (semilla) o } \\
\text { Chihua } \\
\end{array}$ & 0.31 & 0.40 & 429.90 & 0.05 & $3,619.04$ & 0.26 \\
\hline Calabacita & 10.51 & 11.54 & $16,226.75$ & 1.73 & $23,488.99$ & 1.72 \\
\hline Chile verde & 6.55 & 9.06 & $27,491.32$ & 2.93 & $94,770.85$ & 6.94 \\
\hline Pepino & 15.34 & 17.74 & $127,933.67$ & 13.63 & $114,095.06$ & 8.35 \\
\hline $\begin{array}{l}\begin{array}{l}\text { Tomate rojo } \\
\text { (Jitomate) }\end{array} \\
\end{array}$ & 13.57 & 14.08 & $69,487.05$ & 7.40 & $56,603.10$ & 4.14 \\
\hline Otros & & & $26,926.23$ & 2.87 & $43,576.71$ & 3.19 \\
\hline $\begin{array}{l}\text { Suma } \\
\text { porcentajes }\end{array}$ & & & & 100 & & 100 \\
\hline
\end{tabular}

Fuente: Elaboración propia con información del SIAP, 2005-2010. 
Por otra parte, la principal diferencia en cuanto al valor de la producción de cultivos cíclicos entre el año 2005 y el 2010 es el precio de los productos en el mercado. Como ejemplo, podemos señalar que el precio promedio del maíz, que es el principal producto de este tipo de cultivos, pasó de 209.21 dólares en 2005 a 288.74 en 2010, lo cual en pesos deflactados a precios de 2011 equivale a 2092.74 y 2696.45 pesos, respectivamente, esto significó un incremento de $28.84 \%$ en términos reales, mientras que en Estados Unidos pasó de 98.41 dólares en 2005 a 186.01en 2010 (véase gráfica 6).

\section{Gráfica 6}

Precios del maíz en Estados Unidos y México (Dólares por tonelada)

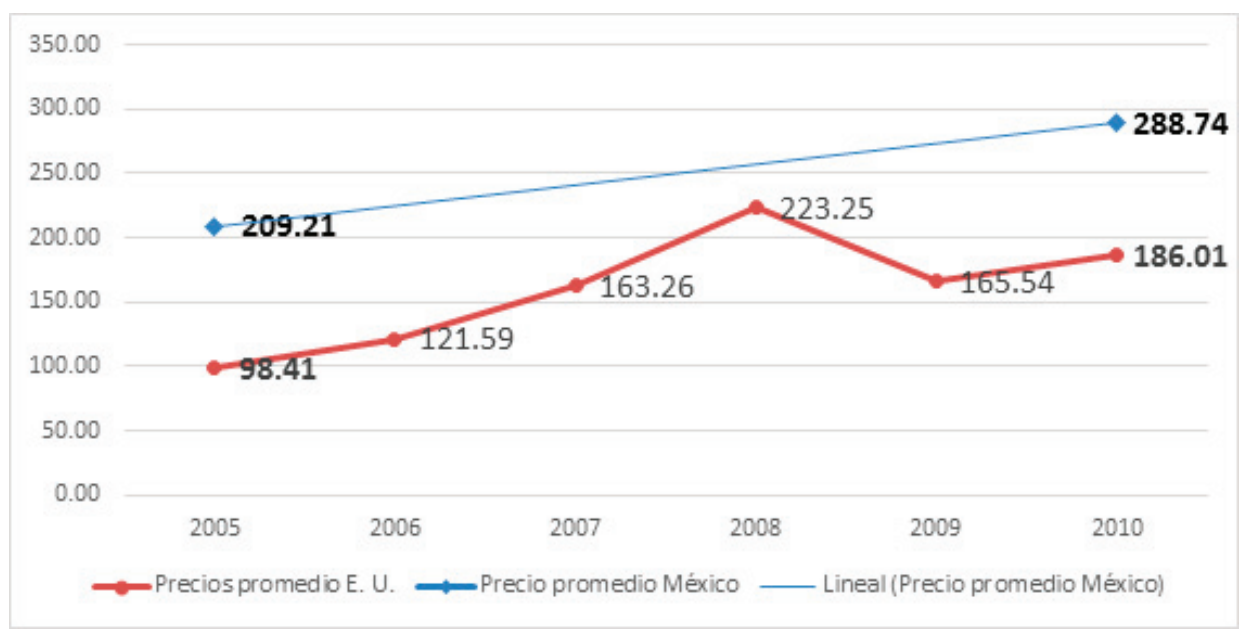

Fuente: Elaboración propia con datos del Banco Mundial (2010).

A pesar de las importaciones que realiza México para satisfacer su demanda interna (10.33 millones de toneladas en 2014(FIRA, 2015), la Secretaría de Agricultura, Ganadería, Desarrollo Rural, Pesca y Alimentación (Sagarpa) reporta que la producción nacional de maíz pasó de 19.3 millones de toneladas en el año 2005 a 24.4 millones de toneladas en el año 2008, lo que significó un aumento en la producción de 26.4\%. 
No obstante, en los municipios indígenas no fue así, pasaron de 351,445 toneladas en 2005 a 359,215 toneladas en 2010, un incremento de $2.2 \%$ solamente. En ese sentido, debemos resaltar qué de conformidad con la perspectiva de la economía campesina, si bien en periodos en los que se da un deterioro en los precios de mercado es posible encontrar que se mantienen e incluso se incrementan los niveles de producción, también encontramos que en periodos de incremento en los precios de mercado la producción se mantiene estable en las comunidades y pueblos indígenas, es decir, que no predomina una racionalidad económica de acumulación de ganancias.

Por otra parte, tenemos que en el periodo 2000-2010 se ha dado un incremento importante en el valor de la producción agrícola de los 84 municipios indígenas que analizamos, fundamentalmente por dos razones: el incremento del precio de mercado de algunos cultivos cíclicos como el maíz, lo que no ha conducido a un incremento de su producción ni de la superficie sembrada, y el incremento de la producción y valor de cultivos perennes. Los cultivos cíclicos de los 84 municipios entre los años 2005 y 2012 fue 49\% superior al promedio de los 468 municipios indígenas; mientras que el valor promedio de la producción de los cultivos perennes es superior en $134 \%$ (véase gráfica 7 ).

\section{Gráfica 7}

Comparativo valor promedio de producción de cultivos cíclicos y perennes por municipio (468 versus 84 municipios indígenas), 2005-2012

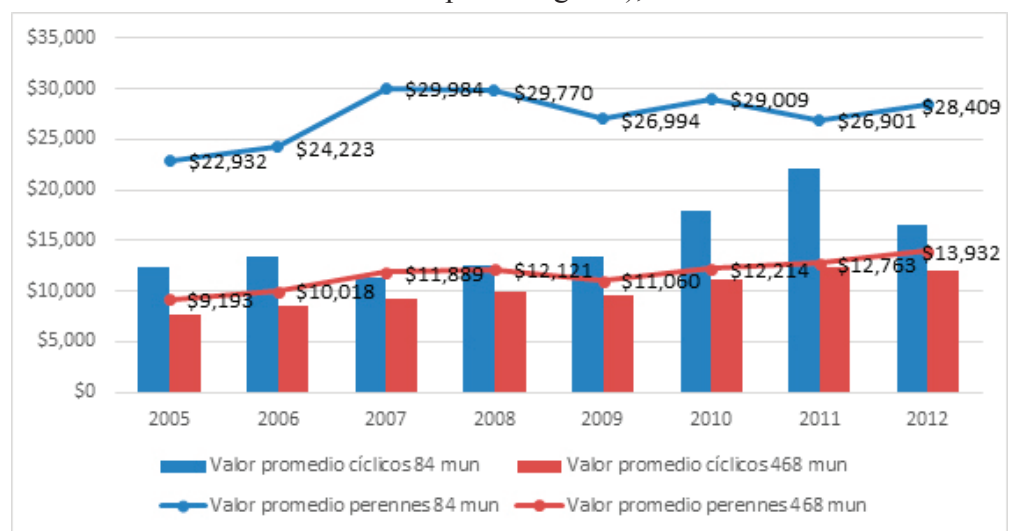

Fuente: Elaboración propia con información del SIAP, 2005-2012. 


\subsection{Correlación entre la producción agrícola con los niveles de pobreza, marginación y desarrollo humano}

Como se mencionó antes, para los 84 municipios de nuestro estudio existe una disminución de la pobreza alimentaria de $6.7 \%$ en el periodo 1990 2010 mientras que, a su vez, se da un incremento en la producción agrícola. En una primera relación estadística se encontró que, efectivamente, en el periodo 2000 - 2010 hay una correlación negativa entre la producción agrícola y los niveles de pobreza de los 84 municipios analizados de -.05 pero con un $\mathrm{t}=-\mathbf{0 . 4 5}$, lo que indica que no es significativa la diferencia con respecto a cero, es decir, se acepta la hipótesis nula de $r_{x y}=0$. Lo que significa que no es robusta la correlación negativa, sin embargo, el signo negativo nos permite augurar que con mayor número de datos la tendencia pueda prevalecer. Como se puede apreciar en la gráfica 8 , la línea de asociación de ambas variables muestra una pendiente negativa, esto es, en la medida que crece el valor de la producción agrícola disminuyen los porcentajes de pobreza alimentaria de la población de los municipios estudiados. ${ }^{2}$

\section{Gráfica 8}

Correlación entre crecimiento del valor de la producción agrícola y reducción de la pobreza alimentaria en 84 municipios indígenas, 2000-2010

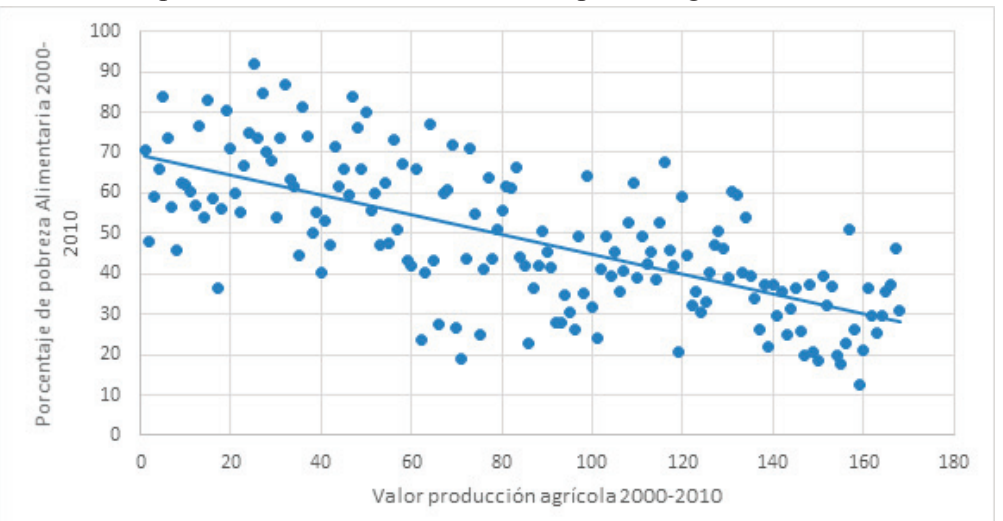

Fuente: Elaboración propia con datos de SIAP y de Coneval, 2000-2010.

2 Se utilizó la línea de pobreza alimentaria rural de Coneval para los años 2000 y 2010. 
Asimismo, se encontró que existe una correlación positiva entre la producción agrícola y el IDH de los 84 municipios de 0.28 , con un $\mathrm{t}=2.64$ lo que indica que es significativa la diferencia con respecto a cero al 99\%, es decir se acepta la hipótesis alternativa de $r_{x y} \neq 0$. Esto significa que la correlación positiva es robusta. La línea de asociación de estas dos variables muestra una correlación positiva, lo que significa que en la medida que crece el valor de la producción agrícola se da un aumento en el IDH de la población de los municipios mencionados (véase gráfica 9).

\section{Gráfica 9}

Correlación entre crecimiento de la producción agrícola y el índice de desarrollo humano en 84 municipios indígenas, 2000-2010

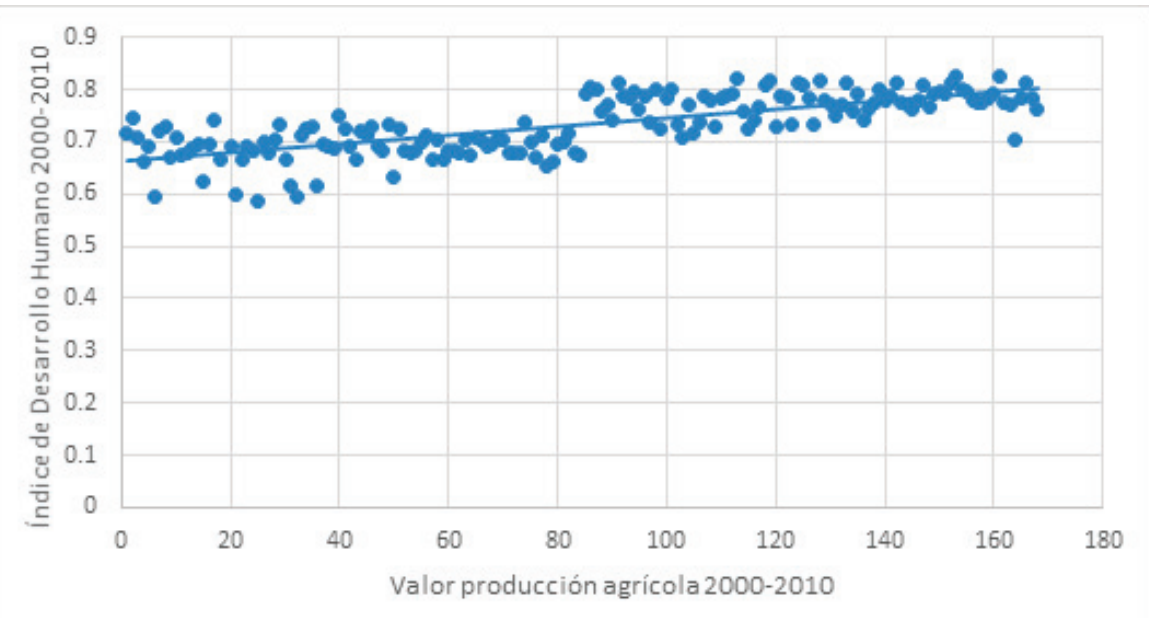

Fuente: Elaboración propia con datos de SIAP y del PNUD, 2000-2010.

Finalmente, como se esperaba, también existe una correlación negativa entre la producción agrícola y los niveles del Índice de Marginación de los 84 municipios estudiados de -0.19 con un $t=-1.75$ lo que indica que es significativa la diferencia con respecto a cero, es decir se acepta la hipótesis alternativa de $\mathrm{r}_{\mathrm{xy}} \neq 0$ al $90 \%$. Como se puede apreciar en la gráfica 10, la línea de asociación de dichas variables muestra una correlación negativa, lo que significa que en la medida que crece el valor de la producción agrícola se da una disminución en los niveles de marginación de los municipios de referencia. 


\section{Gráfica 10}

Correlación entre crecimiento de la producción agrícola y el índice de marginación en 84 municipios indígenas, 2000-2010

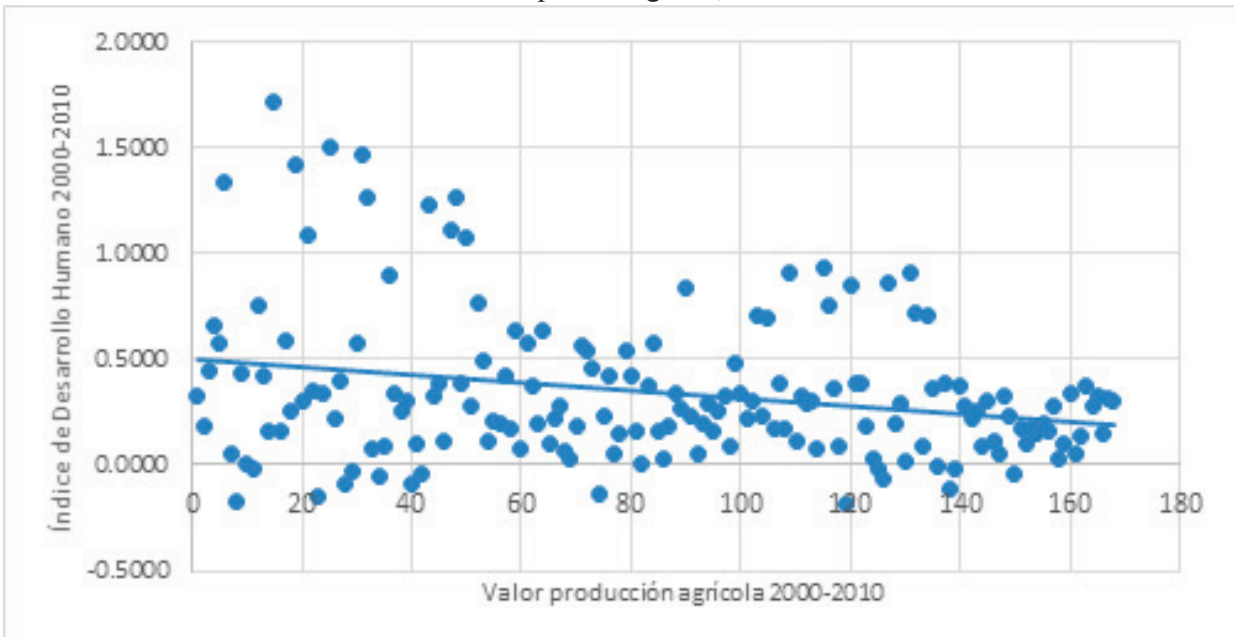

Fuente: Elaboración propia con datos de SIAP y de Conapo, 2000-2010.

\section{CONCLUSIONES}

La importancia del sector agrícola ha sido minimizada a lo largo del modelo de promoción de exportaciones, existen una serie de medidas económicas contra las que la sociedad principalmente indígena tiene que luchar para mantener e incrementar su producción. A pesar de ello, en este artículo se muestra que existen municipios indigenas que han logrado mejorar sus condiciones agrícolas productivas y que existe una correlación negativa entre esta variable y la pobreza y marginación, y positiva con el IDH.

Es necesario destacar las estrategias de sustitución parcial de la producción agríciola de productos perennes y ciclicos, a nuestro juicio este ha sido uno de los elementos que han abonado en la conformación de los resultados que aquí se presentan. La producción de granos básicos para las comunidades, como maíz, frijol e incluso la soya no se han abandonado, muestran unicamente una leve disminución, pero la expansión de la producción de productos perenes, que son los que se comercializan, 
ha constribuido de manera significativa en los resultados, en cuanto a marginación, pobreza e IDH, al elevar los ingresos de los municipios.

Las correlaciones nos proporcionan evidencia de que existen formas de mejoramiento en el bienestar en los municipios indígenas en IDH y marginación, aunque en los niveles de pobreza no es robusto el resultado pero mantiene la correlación negativa. Estas formas de disminución de la marginación y mejoramiento en el IDH no pueden ser explicadas por la teoría económica convencional, fundamentalmente por la forma en la que los ingresos derivados de las actividades económicas se reparten. Existe una forma de racionalidad socio-productiva que esta vinculada a la racionalidad que la economía campesina postula en los municipios indigenas. Dicha racionalidad, junto con la diversificación productiva, ha permitido generar beneficios que se reparten en remuneracionees al trabajo de manera más equitativa que en el capitalismo.

Este tipo de resultados nos muestra que existe una necesidad amplia de entender las formas en las que las economías indigenas se están desenvolviendo y nos puede dar luz respecto a los estudios propiamente de pobreza, el surgimiento de dinámicas económicas de desarrollo muy particulares y mecanismos de distribución del ingreso más equitativos. Además posiciona un sector que practicamente en nuestro país se ha considerado como atrasado, el sector agrícola juega y jugará un papel central en el abatimiento de la marginación, especialmente por el contexto ecológico y climático en el que se necuentra la humanidad.

\section{REFERENCIAS}

Altieri, M. y V.M.Toledo. 2011. "The agroecological revolution of Latin America: rescuing nature, securing food sovereignity and empowering peasants", The Journal of Peasant Studies 38 (3): 587-612. Disponible en: http://www.earthedintl.org/CourseMatls/ SustCentralAm/Readings/06_Agroecology.pdf

Banco Mundial. 2005. Generación de ingresos y protección social para los pobres. Disponible en: http://www-wds.worldbank.org/external/ 
default/WDSContentServer/WDSP/IB/2006/07/27/000012009_200 60727155124/Rendered/PDF/368530SPANISH01d0328670rev01P UBLIC1.pdf

2010. Producción agrícola. Datos de Indexmundi. Disponible en: http://www.indexmundi.com/es/precios-de mercado/?mercancia=m aiz\&meses $=120 \&$ moneda $=\mathrm{mxn}$

Barkin, D. 2001. La nueva ruralidad y la globalización, en E. Pérez y M.A. Farah (comps.) La nueva ruralidad en América Latina. Maestría en desarrollo rural 20 años, volumen 2. Bogotá: Pontificia Universidad Javeriana.

. 2004 "El desempeño ambiental en México", Comercio Exterior, 54(12):1040-1055. Disponible en: http://revistas.bancomext.gob. $\mathrm{mx} / \mathrm{rce} / \mathrm{magazines} / 73 / 1 / \mathrm{RCE} 1 . p d f$

Barkin, David y M. Rosas. 2006. ¿Es posible un modelo alterno de acumulación? Polis, 5(013), Disponible en: https://www. researchgate.net/publication/26462810_Es_posible_un_modelo_ alterno_de_acumulacion

Borrini-Feyerabend, G., M.P. Pimbert, M. T. Farvar, A. Kothari y Y. Renard. 2004. Sharing power: Learning by doing in co-management of natural resources throughout the world. Tehran, Iran: IIED AND IUCN/ CEESP/CMWG. Disponible en: http://www.diversefoodsystems. org/SharingPowerChapters.html

Bray, David y L. Merino. 2004. Community forests of Mexico. Achievements and challenges, México, Consejo Civil Mexicano para la Silvicultura Sostenible, $32 \mathrm{pp}$. Disponible versión español en: http://www2. inecc.gob.mx/publicaciones/consultaPublicacion.html?id_pub=431

Comisión Nacional para el Desarrollo de los Pueblos Indígenas (CDI). 2006. Regiones indígenas de México. Disponible en: http://www. cdi.gob.mx/regiones/regiones_indigenas_cdi.pdf . 2011. Bases de datos 2005 y 2010 de las "Cédulas de información básica de los pueblos indígenas de México”, recuperado 2-XI-2011: http://www.cdi.gob.mx/index.php?option=com_content\&view= article \&id=1327: cedulas-de-informacion-basica-de-los-pueblosindigenas-de-mexico- $\&$ catid $=38 \&$ Itemid $=54$ 
Consejo Nacional de Evaluación de la Política de Desarrollo Social (Coneval). 2012. Medición de la pobreza 2012. Anexo estadístico de resultados nacionales 2008-2012 sin combustible. Recuperado 23-XI-2013:http://www.coneval.gob.mx/Medicion/Paginas/ Medici\%C3\%B3n/Pobreza\%202012/Anexo_estadistico_ Resultados_nal_2008-2012_sin_combustible.aspx . 2013. Evaluación de impacto de la estrategia 100x100. Disponible en: http://www.coneval.gob.mx/Informes/Evaluacion/Impacto/ Evaluacion_de_impacto_de_la_Estrategia_100x100.pdf

Consejo Nacional de Población (Conapo). 2012. Índice de marginación 2000-2010, México. Disponible en: http://www.conapo.gob.mx/en/ CONAPO/Indices_de_Marginacion 2010. Anexo C. Metodología de estimación del índice de marginación por localidad. Disponible en: http://www.conapo.gob.mx/work/ models/CONAPO/indices_margina/2010/anexoc/AnexoC.pdf

Cortés, F. y D. Vargas. 2011. "Marginación a través del tiempo: a propósito del índice de Conapo”, Estudios sociológicos, XXIX (86): 361-387. 2013. La dependencia temporal de la marginación municipal en México 1990-2010: una tercera mirada al índice de marginación. Documento de trabajo No. 1. Programa Universitario de Estudios del Desarrollo de la UNAM. Disponible en: http://www.pued.unam. $\mathrm{mx} /$ archivos/opinion/001.pdf

Díaz, Floriberto. 2004. Comunidad y comunalidad, Culturas populares e indigenas, pp. 365-373. Disponible en: http://indigenasdf.org.mx/ images/documentos/pdf/comunalidad_floriberto.pdf

Fideicomisos Instituidos en Relación con la Agricultura, FIRA. (2015). Panorama Agroalimentario. Dirección de Investigación y Evaluación Económica y Sectorial. Maíz 2015. Recuperado el 1 de agosto de 2016 de https://www.gob.mx/cms/uploads/attachment/file/61952/ Panorama_Agroalimentario_Ma_z_2015.pdf

Estrategia 100x100. Recuperado el 23 de noviembre de 2013, de: http:// www.estrategia100x100.gob.mx/index.php?muest=2

Freunn, John y G. Simon. 1994. Estadística elemental, México: Prentice Hall Hispanoamaericana. 
Fuente Carrasco, M.E. 2009. "Nueva ruralidad comunitaria y sustentabilidad: contribuciones al campo emergente de la economía ecológica", Revista Iberoamericana de Economía Ecológica, 13: 55-69. Disponible en: http://www.redibec.org/IVO/rev13_04.pdf

García Lobo, L.N. y M. Quintero Rizzuto. 2009. "Desarrollo local y nueva ruralidad”, Economía, 28: 191-212. Disponible en: http://www. redalyc.org/pdf/1956/195617795009.pdf

Gomero, L. y H. Velásquez. 2003. "Evaluación de la sustentabilidad del sistema de algodón orgánico en la zona de trópico húmedo del Perú", LEISA Revista de Agroecología, ocho estudios de caso. Disponible en: http://www.agriculturesnetwork.org/magazines/latin-america/ ocho-estudios-de-caso/evaluacion-de-la-sustentabilidad-delsistema-de/at_download/article_pdf

Gobierno Federal. 2012. Estrategia 100 X 100, Secretaría de Desarrollo Social. Estrategia 100x100. Recuperado 23-XI-2013: http://www. estrategia100x100.gob.mx/index.php?muest=2

Grajales Ventura, S. y L. Concheiro Bórquez. 2009. "Nueva ruralidad y desarrollo territorial. Una perspectiva desde los sujetos sociales", Veredas, 18: 145-167.

Grammont, Hubert. 2004. "La nueva ruralidad en América Latina", Revista Mexicana de Sociología, 66: 279-300. Disponible en: https://www. researchgate.net/publication/275883841_La_nueva_ruralidad_en_ America_Latina

Gujarati, Damodar y D. Porter. 2010. Econometría, México: McGrawHill. Hall, Gillette y H.A. Patrinos. 2006. Pueblos indígenas, pobreza y desarrollo humano en América Latina 1994-2004, Banco Mundial/Mayol ediciones. Disponible en: http://www.coedu.usf.edu/zalaquett/SIP pobreza/Pobreza_Etnicidad.pdf

Hilliard, T., M. Tattersfield, A. Rozum y S. Kunickis. 2006. Iniciativa trinacional sobre la calidad del agua y la agricultura, tecnologías actuales: experiencia compartidas, Tri-National Initiative: Case Studies, Agriculture and Agri-Food Canada, Prairie Farm Rehabilitation Administration, Secretaria de Medio Ambiente y Recursos Naturales, U.S. Department of Agriculture, Cooperative 
State Research, Education, and Extension Service, U.S. Department of Agriculture, Natural Resources Conservation Service. Disponible en: http://www.iisd.org/pdf/2006/natres_tri_nat_case_studies_es.pdf López, R. 2007. "El empoderamiento del manejo forestal comunitario en Oaxaca. La unión de comunidades forestales y ejidos de Oaxaca 1985-1996", en D. Bray, L. Merino Pérez y D. Barry (comps.) Los bosques comunitarios de México. Manejo sustentable de paisajes forestales, México, INE, Secretaría de Medio Ambiente y Recursos Naturales. Disponible en: http://www2.inecc.gob.mx/publicaciones/ libros/532/cap6.pdf

Mantilla, J. 2005. "Cultivo ecológico de plantas medicinales y aromáticas: ampliando las perspectivas económicas en los Andes", LEISA Revista de Agroecología, 21(2): 33-36. Disponible en: http://www. agriculturesnetwork.org/magazines/latin-america/mas-que-el-dinero/ cultivo-ecologico-de-plantas-medicinales-y/at_download/article_pdf

Marañon, Boris y D. López. 2013. Racionalidades y prácticas socioproductivas alternativas para el Buen Vivir, IIE, UNAM. Disponible en: http://ru.iiec.unam.mx/2465/

Martínez Luna, J. 2011. Eso que llaman comunalidad, Conaculta/Secretaría de Cultura, Gobierno de Oaxaca/Fundación Alfredo Harp Helú Oaxaca, AC. Disponible en: https:/es.scribd.com/doc/161779610/ Eso-Que-Llaman-Comunalidad

Mora Rivera, J.J. y H. Cerón Monroy. 2015. "Diversificación de ingresos en el sector rural y su impacto en la eficiencia: evidencia para México", Cuadernos Desarrollo Rural, 12(76): 57-81. Disponible en:http://revistas.javeriana.edu.co/index.php/desarrolloRural/ article/view/12107/11285

Murga, O. 2003. "Mujeres dirigiendo el cambio rural: comité y grupo femenino colonia el Quetzal, Tacaná, Guatemala", LEISA Revista de Agroecología, 18(4): 5-6. Disponible en: http://www. agriculturesnetwork.org/magazines/latin-america/4-las-mujeresasumen-el-cambio/mujeres-dirigiendo-el-cambio-rural-comite-ygrupo/at_download/article_pdf 
Pérez, E. 2001. Hacia una nueva visión de lo rural, en N. Guiarraca (comp.) ¿Una nueva ruralidad en América Latina?, CLACSO. Disponible en:http://biblioteca.clacso.edu.ar/clacso/gt/20100929125458/ giarraca.pdf

Programa de Naciones Unidas para el Desarrollo (PNUD). 2005. Informe sobre desarrollo humano, México 2004. Disponible en: http://www. undp.org.mx/IMG/pdf/Inf-_sobre_Des-_Hum-_Mex_2004.pdf 2010. Informe sobre desarrollo humano de los pueblos indígenas en México. El reto de la desigualdad de oportunidades. Disponible en: http://hdr.undp.org/en/reports/national/latinamericathecaribbean/ mexico/Mexico_NHDR_2010.pdf

. 2014. Informe sobre desarrollo humano. Sostener el progreso humano: reducir vulnerabilidades y construir resiliencia. Disponible en: http://hdr.undp.org/sites/default/files/hdr14-report-es.pdf

Reijntjes, C. 2009. "Los pequeños agricultores: la clave para conservar la biodiversidad", Leisa Revista de Agroecología, 25(1). Disponible en: http://www.agriculturesnetwork.org/magazines/latin-america/1diversidad-de-la-agricultura/los-pequenos-agricultores-la-clavepara-conservar/at_download/article_pdf

Rodríguez Herrera, A. y H. Alvarado. 2008. La innovación social. Aprendizajes para América Latina y el Caribe, Chile: CEPAL. Disponible en: http://www.cepal.org/es/publicaciones/2536-clavesla-innovacion-social-america-latina-caribe

Rosas Baños, M. y D. Barkin. 2009. "Racionalidades alternas en la teoría económica”, Economía: teoría y práctica, 31: 75-98.

Rosas Baños, Mara y M.E. Fuente Carrasco. 2013. "La nueva ruralidad comunitaria y las actividades no-proletarias generadoras de excedentes", en T. Padilla (coord.), Los campesinos y su persistencia en la actualidad mexicana, México: Conaculta/FCE, pp. 428-468.

Rosas Baños, M. y R. Lara Rodríguez. 2013. "Desarrollo endógeno local sustentable y propiedad común: San Pedro El Alto, México", Cuadernos de Desarrollo Rural, 10(71): 59-80. Disponible en: https://www. researchgate.net/publication/262373202_Desarrollo_endogeno_local_ sustentable_y_propiedad_comun_San_Pedro_El_Alto_Mexico 
Rubio, Blanca.2004. Explotados y excluidos: los campesinos latinoamericanos en la fase agroexportadora neoliberal, México: Plaza y Valdés/Universidad Autónoma de Chapingo, 240 pp.

Servicio de Información Agroalimentaria y Pesquera (SIAP). 2015. Generación de estadística básica agropecuaria y pesquera. Disponible en: http://www.siap.gob.mx/opt/estadistica/normatividad/sistema/ nagrop_full.pdf

Torres Torres, Felipe y J. Delgadillo. 2009. "Hacia una política territorial del desarrollo rural de México", Convergencia. Revista de Ciencias Sociales, 16(50): 107-131. Disponible en: http://www.redalyc.org/ articulo.oa? id=10511169005

Toledo, Víctor. 1992. Toda la utopía: el nuevo movimiento ecológico de los indígenas y campesinos de México, en J. Moguel et al. (comps.) Autonomía y nuevos sujetos sociales en el desarrollo rural, México: Siglo XXI Editores. Disponible en: http://nuso.org/media/articles/ downloads/2175_1.pdf

1996. Principios etnoecológicos para el desarrollo sustentable de 165 comunidades campesinas e indígenas, documentos de la Red Latinoamericana y Caribeña de Ecología social, 4 pp.. Disponible en: Disponible en: http://infocuib.laborales.unam.mx/ ec08s02c/ archivos/data/1/12.pdf

.2008. "Metabolismos rurales: hacia una teoría económico-ecológica de la apropiación de la naturaleza", Revista Iberoamericana de Economía Ecológica, 7: 1-26. Disponible en: http://www.redibec. org/IVO/rev7_01.pdf

Van der Ploeg, J. D. 2011. Entrevista radiofónica. Disponible en: http:// www.radiomundoreal.fm/Mas-que-inversion-apropiacion?lang=es

Yúnez Naude, A. 2010. Las políticas públicas dirigidas al sector rural: el carácter de las reformas para el cambio estructural, en Antonio Yúnez (comp.) Los grandes problemas de México, volumen III, Economía, México: El Colegio de México. Disponible en: http://2010.colmex. $\mathrm{mx} / 16$ tomos/XI.pdf 